\title{
Analysis of the Spatial Variation of Soil Salinity and Its Causal Factors in China's Minqin Oasis
}

\author{
Tana Qian, ${ }^{1}$ Atsushi Tsunekawa, ${ }^{1}$ Tsugiyuki Masunaga, ${ }^{2}$ and Tao Wang ${ }^{3}$ \\ ${ }^{1}$ Arid Land Research Center, Tottori University, 1390 Hamasaka, Tottori City 680-0001, Japan \\ ${ }^{2}$ Life and Environmental Science, Shimane University, 1060 Nishikawatsu, Matsue City 690-8504, Japan \\ ${ }^{3}$ Key Laboratory of Desert and Desertification, Northwest Institute of Eco-Environment and Resources, Chinese Academy of Sciences, \\ 320 West Donggang Road, Lanzhou 730000, China
}

Correspondence should be addressed to Tana Qian; qian.tana@gmail.com

Received 30 November 2016; Accepted 26 January 2017; Published 15 March 2017

Academic Editor: Hajime Seya

Copyright (C) 2017 Tana Qian et al. This is an open access article distributed under the Creative Commons Attribution License, which permits unrestricted use, distribution, and reproduction in any medium, provided the original work is properly cited.

Land salinization and water resource deterioration negatively affect irrigated agriculture in arid and semiarid areas by limiting the area of arable land and reducing crop yields. The spatial variation of soil salinity is affected by many factors, and their interactions are complex. In this study, we utilized grey relational analysis to evaluate the factors that affect soil salinity in China's Minqin Oasis and the interactions among them and then ranked the significance of their impacts on soil salinity for different land use and cover types. The data used in this study include data obtained from soil chemical analyses based on field sampling in 2015 and hydrological data obtained from local government agencies. We found that the main factors that affect soil salinity in the region's sparse grassland are groundwater salinity and vegetation cover; the least important factor was the distance to the nearest irrigation canal. For cropland, the most important factors were the distance to irrigation canals and hydrological factors. By accounting for these factors, it should be possible to manage the region's limited natural water and soil resources more efficiently, while allowing remediation of existing salinized land and helping to maintain sustainable agriculture in this arid land.

\section{Introduction}

In arid northwestern China, a severe water scarcity and growing soil salinization are closely related problems that are strongly affecting agricultural development and sustainability. These problems are especially severe in oasis ecosystems, where the water scarcity and soil salinization have caused an unrepairable loss of productive land within the past few decades and have threatened the sustainability of agriculture and ecosystem stability [1-3].

The Shiyang River Basin, which lies east of the Hexi Corridor in Gansu Province, has been one of China's most important traditional agricultural regions since $121 \mathrm{BC}$. The Shiyang River is the region's primary water resource. It flows from glacial headwaters in the Qilian Mountains to its lower reaches, in a region called the Minqin Oasis, which is surrounded by both gobi (gravel) deserts and sandy deserts [4]. Since the late 1950s, China's government has promoted increased agricultural practices to support the region's rapid population growth. This has led to a large expansion of cultivation, accompanied by deforestation and reclamation of the region's grasslands. The requirement for irrigation of crops in this arid region has expanded rapidly. Together, these changes have contributed to the degradation of oasis ecosystem services such as freshwater provision and desertification control $[5,6]$.

Due to a lack of long-term water resources planning in the Shiyang River Basin, the distribution of water resources between the river's middle and lower reaches is heavily unbalanced, with excessive withdrawals of water upstream of the oasis [7]. In addition, the water supply to the Minqin Oasis is controlled by management of the giant upstream Honyashan Reservoir and the construction of an extensive network of irrigation canals. According to data from the Gansu Shiyang River Basin Administrative Bureau, the surface runoff flowing into the Minqin Oasis from the upper 
and middle reaches of Shiyang River has decreased rapidly, from $4.931 \times 10^{8} \mathrm{~m}^{3}$ per year in the 1960 s to $1.218 \times 10^{8} \mathrm{~m}^{3}$ per year in the 2000s. To meet the high water demand of the Minqin Oasis, groundwater became the primary water resource to support large-scale irrigation, which led to excessive extraction of the groundwater. This, in turn, has had serious environmental consequences, such as strong mineralization of the groundwater, increasing depth to the groundwater table, and rapid salinization of soils [8]. The depth to groundwater in the oasis has increased at an average rate of $0.47 \mathrm{~m}$ per year since 1981 [9].

Furthermore, the increasing depth to the groundwater table has caused an increase in the concentrations of dissolved minerals in the groundwater [8]. The reuse of saline water for crop irrigation, combined with poor drainage systems, has exacerbated the problem and degraded the hydrological ecosystem. The average total dissolved solids (TDS) content of groundwater in the Minqin Oasis reached $6 \mathrm{~g} / \mathrm{L}$, with maximum of over $10 \mathrm{~g} / \mathrm{L}$ [9]. According to China's national standards for drinking-water quality, the maximum concentration level is $1000 \mathrm{mg} / \mathrm{L}$.

In addition, due to the persistent water scarcity and mineralization, many branches of the Shiyang River have gradually dried out and communities of natural vegetation have become seriously degraded or have disappeared [10]. The natural bush communities and man-made shrub plantations fix the region's abundant deposits of sand and provide windbreaks that reduce the erosive power of the wind; the loss of this vegetation due to a lack of sufficient water increases the risk of desertification. In addition, the wetland vegetation that once grew in large areas of the oasis has declined as the wetlands have dried out. These problems have been exacerbated by an improved system of irrigation canals, which has also contributed to increases in the depth to the groundwater table both by increasing water withdrawals and by reducing groundwater recharge; unlike the previously unlined canals, the concrete-lined canals lose relatively little water into the surrounding soil [9]. The effects of the processes leading to degradation of vegetation in the oasis have ultimately resulted in increased sandy desertification [11].

Damage to the environment has been extensive and represents a serious threat to the sustainability of social and economic development in the Minqin Oasis. In agriculture, saline irrigation water not only restricts the growth of all crops other than those with high salt-tolerance and droughttolerance, but also aggravates the formation of secondary salinization, which results from salt accumulation in the soil under the strong evaporation produced by the dry atmosphere. Irrigation in Minqin Oasis farmland is controlled by canals lined with cement cobble and concrete to improve irrigation efficiency. However, in contrast with the original unlined canals, this leads to reduced groundwater recharge and contributes to the deepening groundwater table [4]. Flood and furrow irrigation are widely used in the Minqin Oasis, and together they exacerbate the process of secondary salinization. Unfortunately, there is insufficient freshwater available to leach the accumulated salt below plant rooting depth throughout the oasis.
As a result of these factors, the land area that is experiencing severe secondary salinization has increased in the oasis. The average salt content of the soil is up to $16.7 \mathrm{~g} / \mathrm{kg}$ [11]. More than 59\% of the irrigated agricultural land has been abandoned because of the combination of water scarcity and the adverse effects of secondary salinization [12]. From 2005 to 2011, the local government organized emigration of two subvillages in Huqu District, with a total population of 1868 (1000 people for 2005, 250 people for 2006, 534 people for 2007, and 84 people for 2011), which has suffered from a growing water scarcity, sand invasion, and soil salinization [9]. Since the $1960 \mathrm{~s}, 2.52 \times 10^{4} \mathrm{~km}^{2}$ of farmland in the oasis has been abandoned [5]. However, the low income of the farmer households who were forced to emigrate and the sustainability of water usage in their resettlement area remain important social, economic, and environmental issues [13].

Because of its severity, land salinization has received much attention from researchers. Although the salinization is affected by many factors [1], the interaction among the factors responsible for different types and intensities of salinization of different land use and cover types is still inadequately understood. To provide this information, we began a study of the Minqin Oasis. Our main objectives were to (a) analyze the spatial variability of soil salinity, (b) analyze the factors that affect soil salinity, and (c) rank the importance of these factors based on land use and cover types. To accomplish these goals, we applied the technique of grey relational analysis to the field survey data, supported by geographical information system (GIS) tools. We also took advantage of government statistical records and remote sensing data in our statistical analysis and relational factor analysis.

\section{Methods}

2.1. Study Area. The Huqu region is located on the downstream alluvial plain of the Shiyang River Basin, in the northern part of the Minqin Oasis. The terrain is relatively flat, with an elevation that ranges from 1254 to $1376 \mathrm{~m}$ asl. It covers an area of $1430 \mathrm{~km}^{2}$ and is located between $38^{\circ} 42^{\prime} \mathrm{N}$ and $39^{\circ} 10^{\prime} \mathrm{N}$ and between $103^{\circ} 19^{\prime} \mathrm{E}$ and $103^{\circ} 49^{\prime} \mathrm{E}$ (Figure 1(a)). The region is surrounded by the Badan Jaran Desert to the west and north and by the Tengger Desert to the east. The region has a temperate continental arid climate, with a mean annual temperature of $7.8^{\circ} \mathrm{C}$ (monthly means range from $-8.6^{\circ} \mathrm{C}$ in January to $21.8^{\circ} \mathrm{C}$ in August). Total annual precipitation averages $110 \mathrm{~mm}$, but the potential evaporation ranges between 2000 and $2600 \mathrm{~mm}$. The mean annual wind speed is $2.8 \mathrm{~m} / \mathrm{s}$, but the highest wind speed can reach $23 \mathrm{~m} / \mathrm{s}$, and winds strong enough to entrain sand occur 139 days per year on average [9].

The main soil types are grey-brown desert soil, sandy soil, solonchak, meadow soil, and anthropogenic-alluvial soil [4]. The main soil type in croplands is a silty clay or a sandy silt. The major crops include cereals (spring wheat, summer maize) and cash crops (cotton, melon, and fennel). Native vegetation includes drought-resistant shrubs, salt-resistant shrubs, and perennial sand-loving herbaceous plants (e.g., Elaeagnus angustifolia, Populus euphratica, Salix purpurea, 


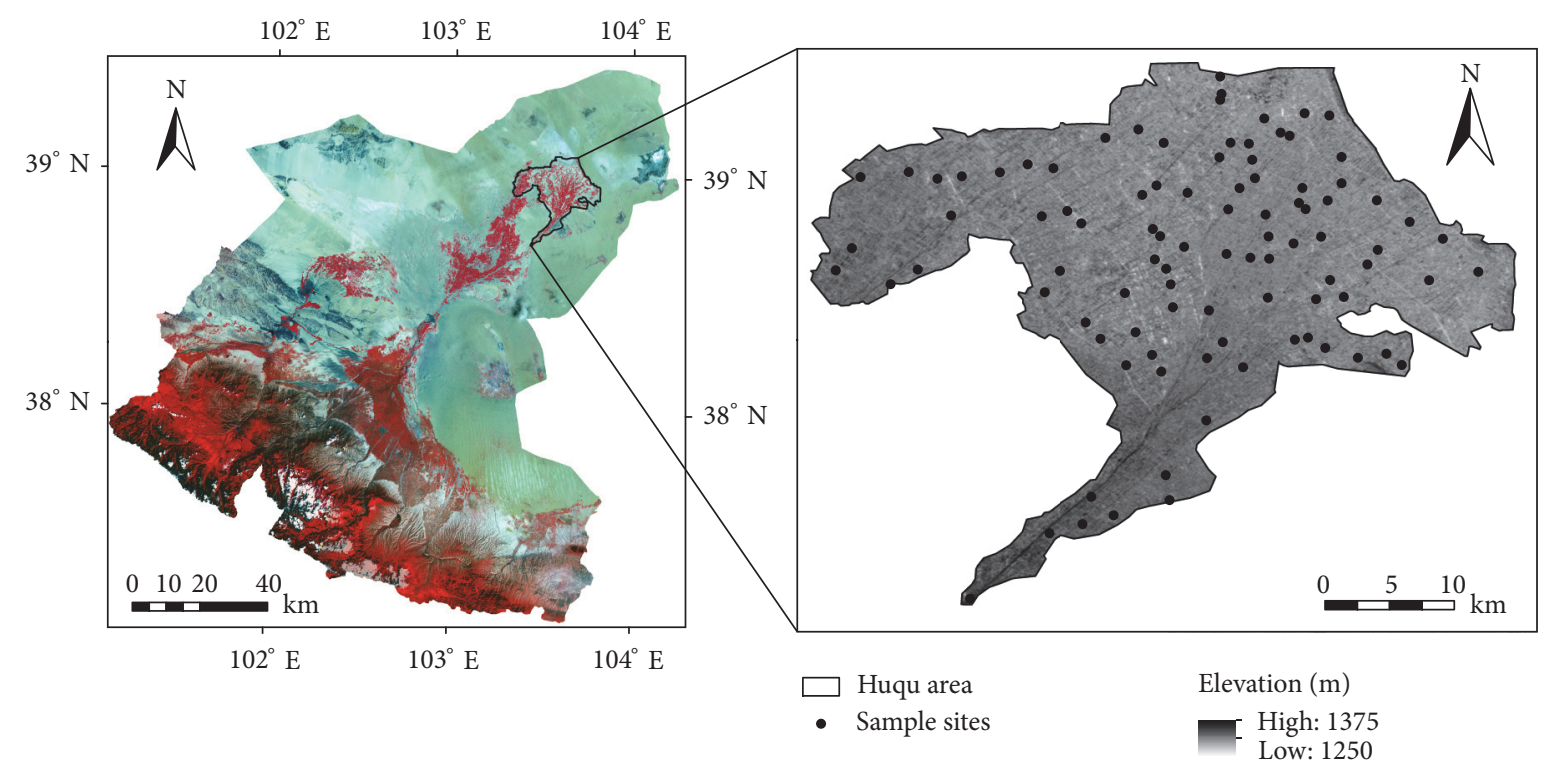

(a)

(b)

FIgure 1: The location of the study area (the Huqu region) within Shi Yang River Basin. (b) Locations of the 94 soil samples analyzed in the present study.

and Agriophyllum squarrosum) [14]. Because most of the grassland area in the oasis was suitable for cultivation, very little natural grassland remains; however, sparse grassland has developed where cultivated land was abandoned for more than decades.

We chose the Huqu region as our study area because of the existence of both the original salt accumulation (primary salinization) and irrigation-caused salt accumulation (secondary salinization). The area has been suffering from severe ecological problems for decades, including high mineralization of groundwater, salinization, and desertification characterized by sand invasion, as well as from social and economic pressures caused by ecological emigration and cropland abandonment.

2.2. Soil Sampling and Laboratory Analysis. The field dataset was obtained during April 2015, when the salt concentration in surface soils reaches its maximum in this region. In April, the low precipitation combines with a high evaporation rate to cause salt from deeper soil layers to migrate upwards and accumulate near the surface of the soil [15]. We obtained 94 surface soil samples (Figure 1(b)) to a depth of $10 \mathrm{~cm}$ from unused land (9 samples from shrubland, 5 samples from abandoned land, 46 samples from sparse grassland, and 13 samples from saline wasteland) and cropland (used to grow wheat, sunflower, alfalfa, goji berry, and fennel). The sites were selected based on the results of previous soil salinity studies and Google Earth images, and each sample site represented an area of $90 \mathrm{~m} \times 90 \mathrm{~m}$. For each sample point, we combined five topsoil samples into a single composite sample, which we used to represent the value of the soil chemical parameters at that site. The location of each sample point was recorded with a MAP64SJZ GPS receiver (Garmin, Olathe,
KS, USA) and we photographed the site. The characteristics of the soil surface, the land use and cover types surrounding the site, and the vegetation cover were recorded in a field notebook. We also consulted local farmers to learn about historical land use and cover types.

Soil moisture was assessed during the soil sample collection. The samples were sealed into weighed, empty specimen boxes and their total weights were measured. When we returned to the laboratory, we opened the boxes and ovendried the samples for 24 hours at $105^{\circ} \mathrm{C}$ together with the boxes. We calculated the soil moisture content (SMC) as a percentage of the dry soil weight.

For the chemical analysis, the samples were air-dried, crushed, and passed through a $1 \mathrm{~mm}$ sieve to remove large particles and plant residues. To quantify the soil salinity, we measured the electrical conductivity $\left(\mathrm{EC}_{1: 5}\right)$ in deionized distilled water at $1: 5 \mathrm{~g} / \mathrm{mL}$ soil : water ratio. We calculated the frequency distribution of these values and several associated parameters: the mean, median, standard deviation, skewness, kurtosis, range, and maximum and minimum values. We used version 23 of the SPSS software (http://www.ibm.com/ analytics/us/en/technology/spss/) for our statistical analysis.

We also measured the soil $\mathrm{pH}$. To make the $\mathrm{pH}$ measurements better reflect the water content of the soil under field conditions, we used a $1: 1 \mathrm{~g} / \mathrm{mL}$ soil solution [16].

2.3. GIS and Map Preparation. Maps of the distribution of soil $\mathrm{EC}_{1: 5}$ were prepared to visualize the results at the 94 sample sites. We used version 10.2.1 of the ArcView software (http://www.esri.com). We also visualized the layout of the irrigation canal network, depths to the water table, and TDS data for the water using ArcView. Additional data included an ASTER Global Digital Elevation Model (ASTER GDEM) 
TABLE 1: Definitions of the affecting factors for the reference series (soil $\mathrm{EC}_{1: 5}$ ).

\begin{tabular}{lcc}
\hline Affecting factor & Definition & Measurement \\
\hline$X_{i}(1)$ & Elevation of the sample site & Distance above mean sea level \\
$X_{i}(2)$ & Distance to the nearest irrigation canal & The distance between the sample point and the nearest canal \\
$X_{i}(3)$ & Compound topographic index (CTI) & Defined in Section 2.3 \\
$X_{i}(4)$ & Vegetation cover & The \% coverage of the soil by vegetation \\
$X_{i}(5)$ & Groundwater level & Distance from the ground surface to the top of the groundwater table \\
$X_{i}(6)$ & Groundwater salinity & Total dissolved salt content in the groundwater
\end{tabular}

acquired from https://gdex.cr.usgs.gov/gdex/ at a 30-m resolution. To describe the topographic characteristics of the sample sites, we derived the compound topographic index (CTI), which is widely used in hydrology and terrain-related applications, from the DEM data [17]. CTI is a compound index that is calculated using two primary topographic attributes [18]; it is also known as the steady-state wetness index when it is used to quantify the catenary landscape position [19]. We used the following equation to calculate the CTI values:

$$
\mathrm{CTI}=\ln \left(\frac{\alpha}{\tan \beta}\right)
$$

where $\alpha$ represents the catchment area per pixel, and $\beta$ represents the slope gradient. Low CTI values represent small catchments, steep slopes, and upper catenary positions. High CTI values represent large catchments, gentle slopes, and lower catenary positions with a higher capacity for water accumulation and wetness [20].

2.4. Grey Relation Analysis. A grey relationship is a relationship among different types of data series often with different units of measurement when there is considerable uncertainty and an unsatisfactory sample size [21]. Grey relational analysis (GRA) is a way to identify the key factors that control a system and quantify the influence that each factor exerts on a reference variable [22]. It is often applied in studies that have an insufficient sample size and uncertainty about whether the data is truly representative [21, 23]. The basic idea behind GRA is to compute the strength of the relationship between variables by examining the degree of proximity for certain geometrical figures or the degree of correlation between curves [22]. In this study, we employed GRA to quantify the influence of several factors on the soil salinity of the 94 samples from the Huqu area.

In GRA, the original data series are divided into two types of series: a reference series that will be compared with all other variables and one or more affecting series (one per variable that potentially affects the values in the reference series). The grey strength of the relationship is calculated to represent the relative proximity of two series. A discrete sequence of ranks can then be generated, with the ranks depending on the strengths of each factor's relationship to the reference series. If the strength of the relationship for one affecting series is higher than that of the others, the former series is considered to have a greater influence than the others on the reference series [24].
The first step in GRA is to generate the reference series and the affecting series. Since the range of values and the units of measurement in one data series may differ from those in other series, the original data are first normalized by dividing each value by the mean value in the series, thereby producing a range of values from 0 to 1 , and are then used to calculate the grey relational coefficient between the reference series and the affecting series [25]. The reference series is represented as $x_{0}(k)=x_{0}(1), x_{0}(2), \ldots, x_{0}(n)$, where $k$ is the number of sample data, with $k \in(1,2, \ldots, n)$, and $n$ is the number of factors. Each affecting series is represented as $x_{i}(k)=x_{i}(1), x_{i}(2), \ldots, x_{i}(n)$, where $i$ represents the affecting series. In this study, we used the soil $\mathrm{EC}_{1: 5}(\mathrm{dS} / \mathrm{m})$ as the reference series. Based on our review of the research literature and the mechanisms of salinization, as well as based on data availability, we selected six affecting factors for use as the affecting series (Table 1).

The grey relational coefficient for two series, $\zeta_{i}(k)$, can be calculated as follows:

$$
\zeta_{i}(k)=\frac{\Delta_{\min }+\zeta \Delta_{\max }}{\Delta_{0 i}(k)+\zeta \Delta_{\max }},
$$

where $\Delta_{0 i}(k)=\left\|x_{0}(k)-x_{i}(k)\right\|$ is the absolute difference between the reference factor $x_{0}(k)$ and the corresponding affecting factor $x_{i}(k) ; \zeta$ represents a grey parameter with a value between 0 and 1 , and that is often assigned a value that equaled 0.5 , a value that is commonly used [26]; and $\Delta_{\min }$ and $\Delta_{\max }$ represent the smallest and biggest values, respectively, among all of the $\Delta_{0 i}(k)$ values.

The grey relational grade, $\gamma_{i}$, for the relationship between each affecting series $x_{i}(k)$ and the reference series $x_{0}(k)$ can be calculated by averaging the grey relational coefficient corresponding to each affecting factor:

$$
\gamma_{i}=\frac{1}{n} \sum \zeta_{i}(k)
$$

The ranking of the affecting factors is then conducted based on the computed grey relational grades. As mentioned earlier, a higher value of the grey relational grade indicates a stronger relationship between the two series and suggests that the corresponding affecting factor is closer to the reference series than other affecting factors [27].

\section{Results and Discussion}

3.1. Statistical Analysis. Figure 2 shows the frequency distribution and descriptive statistics for $\mathrm{EC}_{1: 5}$ of the cropland and 


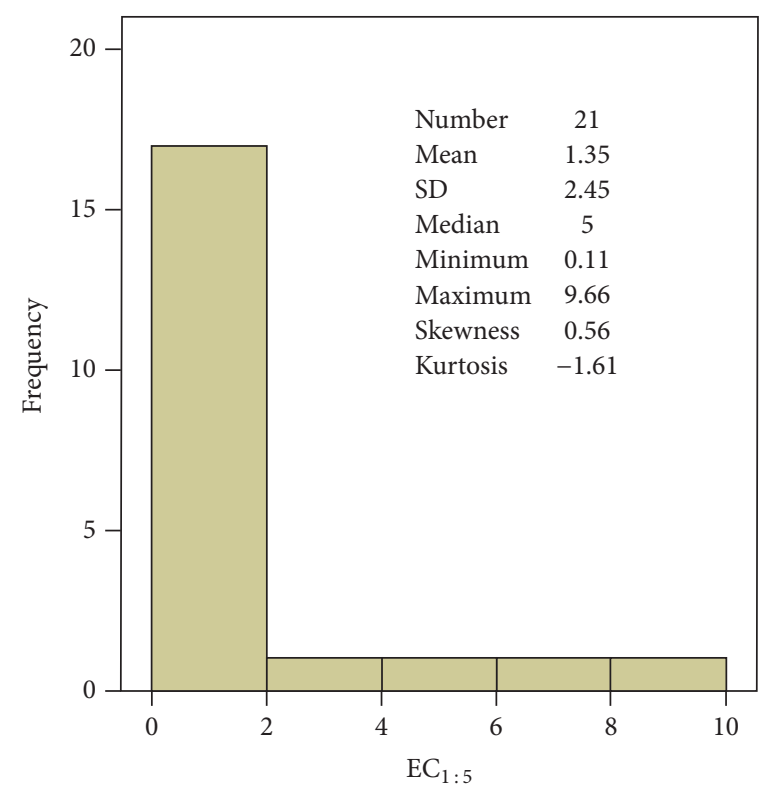

(a)

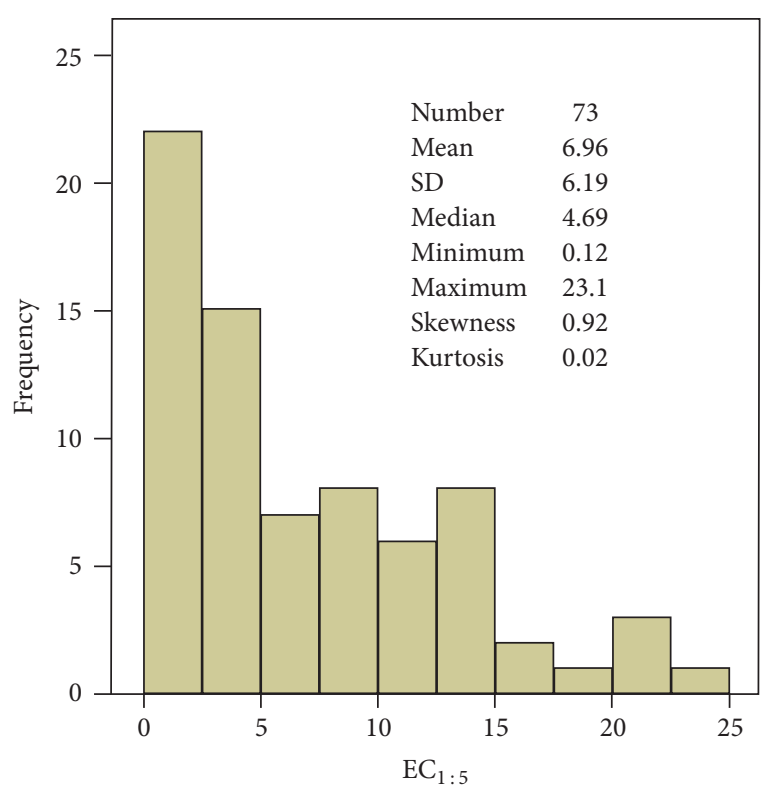

(b)

Figure 2: Histograms of $\mathrm{EC}_{1: 5}$ values for samples from (a) cropland $(n=21)$ and (b) all other land types $(n=73)$ and their associated descriptive statistics.

other land types. 21 soil samples were collected from cropland during the spring, which explains why many samples have a low $\mathrm{EC}_{1: 5}$ value. 73 soil samples were collected from other land types (shrubland, abandoned land, sparse grassland, and saline wasteland). Figure 2 also shows wide variation in the $\mathrm{EC}_{1: 5}$ data, with values ranging from 0.11 to $23.1 \mathrm{dS} / \mathrm{m}$ (two orders of magnitude).

To understand the spatial distribution of the salinity levels, we mapped the distribution of soil $\mathrm{EC}_{1: 5}$ using ArcView based on equal interval method (Figure 3). As the distribution map shows, most of the samples with high $\mathrm{EC}_{1: 5}$ were distributed at the margins of the oasis, but some were distributed in the center; in contrast, the samples with lower $\mathrm{EC}_{1: 5}$ were distributed throughout the oasis.

\subsection{Differences in Soil Salinity among the Different Land Use} and Cover Types. To further explore the characteristics of the distribution of the soil $\mathrm{EC}_{1: 5}$ values in the Huqu area in relation to the land management in the study area, we classified the 94 samples into the five main land use and cover types: cropland, shrubland, abandoned land, sparse grassland, and saline wasteland. Table 2 summarizes the measured values of the various properties of the soil samples.

The coefficient of variation (CV) is the ratio of the standard deviation to the mean and is often used as a general index of variability among the samples [28]. A CV value lower than $0.1(10 \%)$ indicates low variability, whereas a CV value higher than 1.0 (100\%) indicates high variability; intermediate values have moderate variability [29]. Table 2 shows that the $\mathrm{CV}$ values of $\mathrm{EC}_{1: 5}$ for cropland and shrubland were highly variable, with $C V$ values greater than 1.0 , which suggests that $\mathrm{EC}_{1: 5}$ and its distribution pattern are strongly

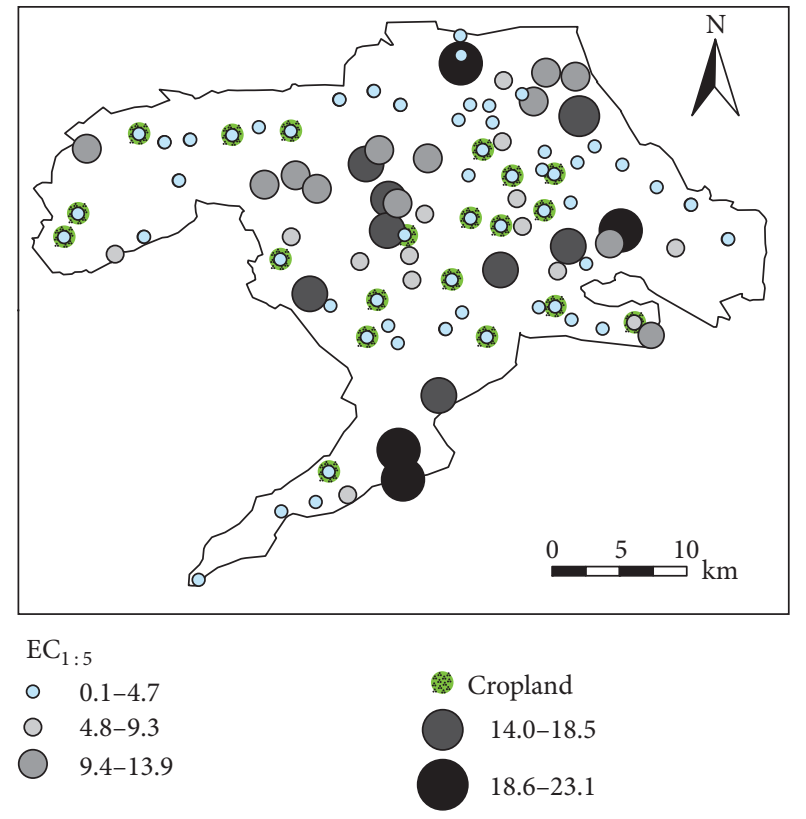

FIGURE 3: Map of the distribution of $\mathrm{EC}_{1: 5}$ values for the 94 soil samples.

influenced by human driving factors such as irrigation and farming activities as well as by the irrigation canal system. Despite regular irrigation, some of the cropland soil $\mathrm{EC}_{1: 5}$ values reached $9.66 \mathrm{dS} / \mathrm{m}$, which indicates the existence of a secondary salinization problem. The shrubland is mainly artificial and has resulted from a local policy to replace cropland with shrubs to combat desertification. The low 


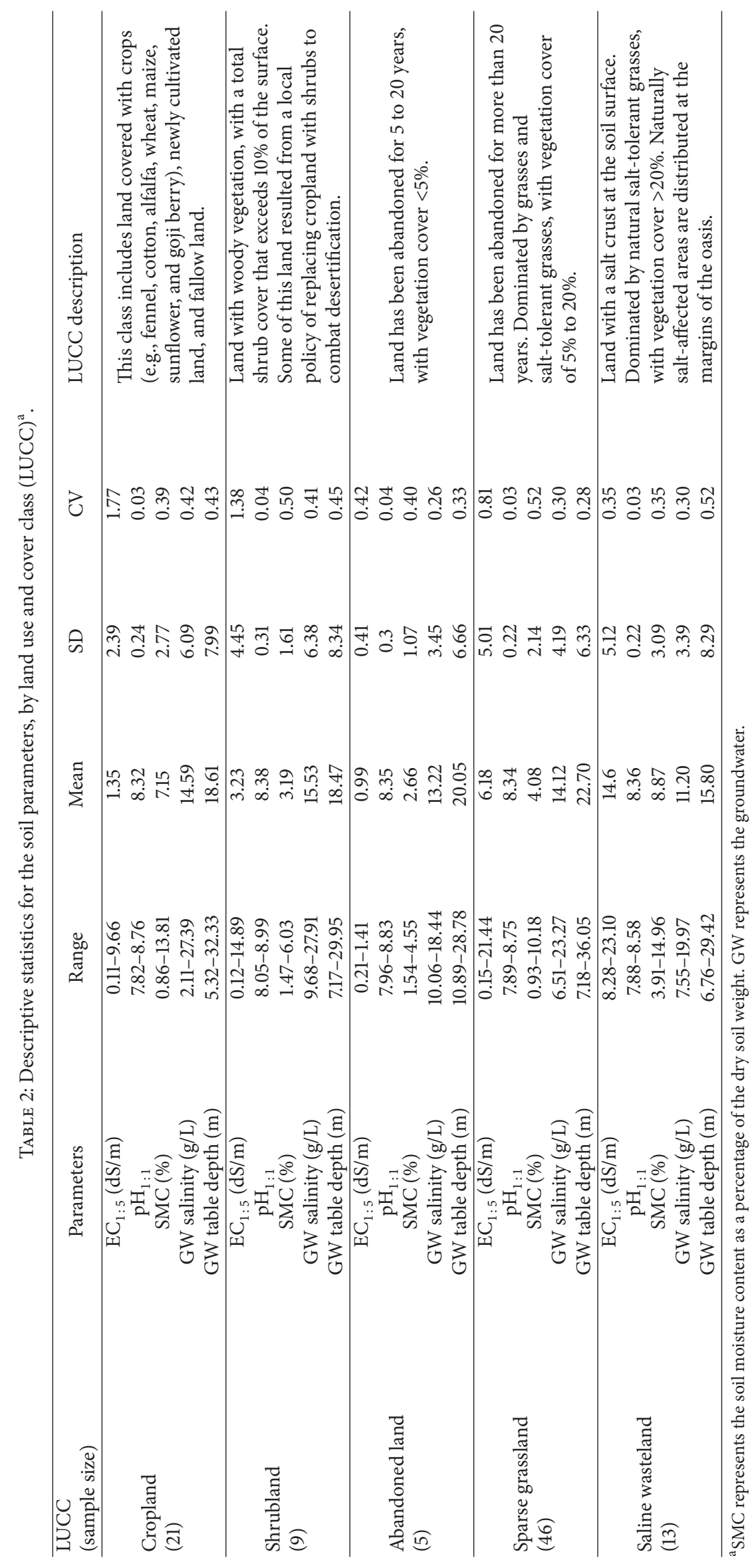


TABLE 3: Grey relational grade $(\gamma)$ and the resulting ranking for each affecting factor.

\begin{tabular}{lccccc}
\hline Reference factor & Affecting factor & Definition & $\gamma$ & Ranking $^{\text {Relationship }^{\mathrm{a}}}$ \\
\hline & $X_{i}(2)$ & Distance to irrigation canals & 0.814 & 1 & Positive \\
& $X_{i}(6)$ & Groundwater salinity & 0.810 & 2 & Negative \\
$X_{0} \mathrm{EC}_{1: 5}$ & $X_{i}(3)$ & CTI & 0.804 & 3 & Positive \\
& $X_{i}(1)$ & Elevation of the sample site & 0.801 & 4 & Negative \\
& $X_{i}(5)$ & Groundwater level & 0.798 & 5 & Negative \\
& $X_{i}(4)$ & Vegetation cover & 0.771 & 6 & Negative \\
\hline
\end{tabular}

${ }^{\mathrm{a}}$ Positive relationships mean that a high value of the affecting factor increased $\mathrm{EC}_{1: 5}$; negative relationships mean that a high value decreased $\mathrm{EC}_{1: 5}$.

TABLE 4: Grey relational grade $(\gamma)$ for each affecting factor and the resulting ranking for the two main land use and cover types.

\begin{tabular}{|c|c|c|c|c|c|}
\hline Reference factor & Affecting factor & Definition & $\gamma$ & Ranking & Relationship $^{a}$ \\
\hline \multicolumn{6}{|c|}{ Cropland } \\
\hline \multirow{6}{*}{$X_{0} \mathrm{EC}_{1: 5}$} & $X_{i}(2)$ & Distance to irrigation canals & 0.847 & 1 & Positive \\
\hline & $X_{i}(5)$ & Groundwater level & 0.787 & 2 & Negative \\
\hline & $X_{i}(3)$ & CTI & 0.783 & 3 & Positive \\
\hline & $X_{i}(1)$ & Elevation of the sample site & 0.780 & 4 & Negative \\
\hline & $X_{i}(6)$ & Groundwater salinity & 0.777 & 5 & Positive \\
\hline & $X_{i}(4)$ & Vegetation cover & 0.760 & 6 & Negative \\
\hline \multicolumn{6}{|c|}{ Sparse grassland } \\
\hline \multirow{6}{*}{$X_{0} \mathrm{EC}_{1: 5}$} & $X_{i}(6)$ & Groundwater salinity & 0.755 & 1 & Positive \\
\hline & $X_{i}(4)$ & Vegetation cover & 0.742 & 2 & Positive \\
\hline & $X_{i}(1)$ & Elevation of the sample site & 0.714 & 3 & Negative \\
\hline & $X_{i}(5)$ & Groundwater level & 0.711 & 4 & Positive \\
\hline & $X_{i}(3)$ & CTI & 0.708 & 5 & Negative \\
\hline & $X_{i}(2)$ & Distance to irrigation canals & 0.662 & 6 & Negative \\
\hline
\end{tabular}

${ }^{\mathrm{a}}$ Positive relationships mean that a high value of the affecting factor increased $\mathrm{EC}_{1: 5}$; negative relationships mean that a high value decreased $\mathrm{EC}_{1: 5}$.

soil moisture content of the shrubland provides evidence of a water scarcity problem. This is consistent with previous research, which showed that shrubs have died in large areas because the groundwater level fell below the level their roots can reach. The maximum $\mathrm{EC}_{1: 5}$ value of shrubland reached $14.89 \mathrm{dS} / \mathrm{m}$, which indicated large amounts of salt accumulation in the topsoil as a result of a high evaporation rate combined with low rainfall and mineralization of the groundwater.

The CV values of $\mathrm{EC}_{1: 5}$ for abandoned land, sparse grassland, and saline wasteland were moderate (between 0.1 and 1.0). These land use and cover types were less strongly affected by human activities. Abandoned land was defined as land that had been abandoned for 5 to 20 years, and sparse grassland has been abandoned for more than 20 years and has begun to develop a grassland ecosystem. The majority of the soil $\mathrm{EC}_{1: 5}$ values for abandoned land were lower than those for sparse grassland, which indicated that soil salinity increased with increasing duration of abandonment. Compared with sparse grassland, the salinity level and moisture content of soils in the abandoned land were lower.

The CV values for SMC for all land use and cover types showed moderate variability ( 0.1 to 1.0$)$. The $\mathrm{pH}_{1: 1}$ of the soil of the study areas ranged from 7.82 to 8.99 (slightly alkaline), and its low CV values $(<0.1)$ indicated slight variation. The mean $\mathrm{pH}_{1: 1}$ for all land use and cover types was greater than 8 , which indicated most of the soil samples are weakly alkaline. The high groundwater salinity $(>11 \mathrm{~g} / \mathrm{L})$ content and deep groundwater table depth $(>15 \mathrm{~m})$ indicated poor water quality and poor access to water, and their low $\mathrm{CV}$ values indicate moderate spatial variability.

3.3. Impact Factors. Many factors, including soil factors, hydrological factors, management factors, and other factors, affected the soil salinization process and its spatial distribution in the Huqu area. Interactions among these factors are complex [30]. Based on the calculated value of the grey relational grade $(\gamma)$, we determined the order of each affecting factor for all 94 samples combined. As shown in Table 3, these values range from 0 to 1 , and we obtained the following ranking of the factors based on the grey relational grades: distance to the nearest irrigation canal $>$ groundwater salinity $>$ CTI $>$ elevation of the sample site $>$ groundwater level $>$ vegetation cover.

Analyzing the grey relationships between the affecting factors and soil $\mathrm{EC}_{1: 5}$ for specific land use and cover types will help us to better understand the interaction between these factors and the salinization processes. To do this, we selected the two main land use and cover types and applied GRA to their affecting factors (Table 4). 
Table 4 shows the calculated grey relational grades for the affecting factors for cropland and sparse grassland. For the cropland soil samples, the distance to the nearest irrigation canals was the most important factor for soil $\mathrm{EC}_{1: 5}$ and had a positive relationship with soil $\mathrm{EC}_{1: 5}$. The greater the distance between the sample sites and the canal, the higher the soil $\mathrm{EC}_{1: 5}$ content. This is because the use of fresh river water as an irrigation source, coupled with the drainage system, greatly, decreased salt accumulation in the topsoil. In contrast, the groundwater salinity had a negative relationship with soil $\mathrm{EC}_{1: 5}$, which was mainly because farmers combined fresh river water with groundwater to irrigate the croplands. The higher groundwater salinity is, the less amount of it can be used for irrigation, and the more river water must be consumed for irrigation, leading to accelerated salt leaching and reducing the salt accumulation in the soil. Some samples were taken from the margins of the oasis, where the groundwater salinity was strongly affected by highly saline desert groundwater. In addition, the groundwater table depth was at least $5.3 \mathrm{~m}$ (Table 2) in those areas with high groundwater salinity. Because this large distance interrupts the capillary rise of water from the groundwater table to the soil surface, salt movement from the groundwater into the topsoil was reduced [31]. The vegetation cover had the weakest impact on the soil $\mathrm{EC}_{1: 5}$ of cropland, mainly because little vegetation had developed at the beginning of the growing season, when we obtained our soil samples.

For sparse grassland, distance to the nearest canal was the weakest affecting factor. This was mainly because the sparse grassland was close to a natural condition because of low intervention by human activities (i.e., after abandonment for more than 20 years). The groundwater salinity had a strong positive relationship with soil $\mathrm{EC}_{1: 5}$ for sparse grassland, which indicated that local-scale hydrological factors affected the distribution and variation of surface soil salinity. The sparse grassland had been abandoned for more than 20 years, and most of the sparse grassland had suffered from secondary salinization. Some of the land has been abandoned for more than 40 years; severe adverse effects of intensive agricultural practices during the 1950s and 1960s made the land unsuitable for cultivation. Excessive groundwater extraction for irrigation caused a rapid deepening of the groundwater table and mineralization of the groundwater. The use of groundwater with a high salt content, coupled with strong evaporation, accelerated salt accumulation in the topsoil. This caused rapid degradation of productive land and, eventually, abandonment of this land. The soil $\mathrm{EC}_{1: 5}$ values in this land could reach as high as the values in saline wasteland. The vegetation cover was the second-strongest affecting factor due to dense growth of halophytes in saltaffected areas [32].

\section{Conclusions}

Salt-affected soils were distributed throughout the Huqu area. Most of the cropland had relatively low soil salinity, but several samples had high $\mathrm{EC}_{1: 5}$, which indicates a high potential for secondary salinization. The saline wasteland had some of the highest salinity values and was concentrated mainly at the margin of the oasis, where there was no irrigation. Secondary salinized land was mainly located in areas of sparse grassland inside the oasis. The CV values of soil $\mathrm{EC}_{1: 5}$ for cropland and shrubland were greater than 1.0, which indicates that soil $\mathrm{EC}_{1: 5}$ and its distribution were strongly influenced by human activities.

Land use practices also strongly influenced the distribution of salt-affected soils. The abandoned cropland had low salinity, but the long-abandoned cropland (which became sparse grassland) tended to have high salinity, sometimes reaching values as high as those in saline wasteland. In addition, transforming cropland to shrubland could result in further land degradation in Huqu area; due to the water scarcity and poor water quality, this change led to higher $\mathrm{EC}_{1: 5}$ and lower SMC. Improved management should focus on these lands to prevent further degradation.

The distance to the nearest irrigation canal was the most important factor for determining the salinity of cropland. The access to fresh river water and good drainage, combined with a deep groundwater table, prevented salt accumulation in the topsoil. However, the use of highly saline water and improper drainage and soil management will increase the risk of secondary salinization in irrigated soils. Therefore, proper irrigation methods, an improved drainage system, and effective soil management will be necessary to prevent nonsalinized cropland from undergoing secondary salinization and to remediate existing salinized cropland.

The small sample size in this study may have made the data less reliable. However, the use of GRA should have mitigated this problem. Nonetheless, obtaining more and better data on water and soil properties would improve the ability to support management of the water and soil resources of the Minqin Oasis, particularly if combined with remote sensing and GIS techniques to improve our ability to detect the distribution of salt-affected soils over larger areas.

\section{Competing Interests}

The authors declare that there is no conflict of interests regarding the publication of this paper.

\section{Acknowledgments}

The authors would like to thank International Platform for Dryland Research and Education, Tottori University, for financial support; Professor Xue Xian, Professor Wang Ninglian, Dr. Huang Cuihua, Dr. Liao Jie, and Dr. Luo Jun from Northwest Institute of Eco-Environment and Resources, CAS, for providing them with the equipment and the assistance in the field; the Minqin Bureaus of Water Resources Management for providing hydrological data; Professor Kitamura Yoshinobu and Professor Fujimaki Haruyuki from Tottori University for the useful advices and equipment; Geoff Hart for helpful advice on early version of this paper. The Landsat dataset is provided by Environmental and Ecological Science Data Center for West China, National Natural Science Foundation of China (http://westdc.westgis.ac.cn). 


\section{References}

[1] P. Rengasamy, "World salinization with emphasis on Australia," Journal of Experimental Botany, vol. 57, no. 5, pp. 1017-1023, 2006.

[2] W. Genxu and C. Guodong, "Water resource development and its influence on the environment in arid areas of China-the case of the Hei River basin," Journal of Arid Environments, vol. 43, no. 2, pp. 121-131, 1999.

[3] C. Tian and H. Zhou, "The proposal on control of soil salinization and agricultural sustainable development in the 21st century in Xinjian," Arid Land Geography, vol. 23, no. 2, pp. 177$181,2000$.

[4] S. Danfeng, R. Dawson, and L. Baoguo, "Agricultural causes of desertification risk in Minqin, China," Journal of Environmental Management, vol. 79, no. 4, pp. 348-356, 2006.

[5] Y. Ma, S. Fan, L. Zhou, Z. Dong, K. Zhang, and J. Feng, “The temporal change of driving factors during the course of land desertification in arid region of North China: the case of Minqin County," Environmental Geology, vol. 51, no. 6, pp. 999-1008, 2007.

[6] R. T. Munang, I. Thiaw, and M. Rivington, "Ecosystem management: tomorrow's approach to enhancing food security under a changing climate," Sustainability, vol. 3, no. 7, pp. 937-954, 2011.

[7] G. Schneier-Madanes and M. F. Courel, Water and Sustainability in Arid Regions: Bridging the Gap between Physical and Social Sciences, Springer, Dordrecht, The Netherlands, 2009.

[8] D. K. Vajpeyi, M. Bondes, A. M. Buainain et al., Climate Change, Sustainable Development, and Human Security: A Comparative Analysis, Lexington Books, 2013.

[9] Local Chronicles Office of Minqin County, Annals of Shi Yang River, Wuwei Guangxin Kemao Printing Co. Ltd, 2014.

[10] Z. L. Huo, S. Y. Feng, S. Z. Kang, S. J. Cen, and Y. Ma, "Simulation of effects of agricultural activities on groundwater level by combining FEFLOW and GIS," New Zealand Journal of Agricultural Research, vol. 50, no. 5, pp. 839-846, 2007.

[11] J. Ma and H. Wei, "The ecological and environmental problems caused by the excessive exploitation and utilization of groundwater resources in the Minqin Basin, Gansu province," Arid Zone Research, vol. 20, no. 4, pp. 261-265, 2002.

[12] C. Guo, L. Wang, F. Han et al., "Studies of soil physical property on different abandoned lands in the Minqin Oasis, downstream of the Shiyang River," Agricultural Science \& Technology, vol. 16, no. 5, pp. 1014-1018, 2015.

[13] Y. Li, D. López-Carr, and W. Chen, "Factors affecting migration intentions in ecological restoration areas and their implications for the sustainability of ecological migration policy in arid Northwest China," Sustainability, vol. 6, no. 12, pp. 8639-8660, 2014.

[14] S. Kang, X. Su, L. Tong et al., "The impacts of human activities on the water-land environment of the Shiyang River basin, an arid region in northwest China," Hydrological Sciences Journal, vol. 49, no. 3, p. 427, 2004.

[15] A. A. Elnaggar and J. S. Noller, "Application of remote-sensing data and decision-tree analysis to mapping salt-affected soils over large areas," Remote Sensing, vol. 2, no. 1, pp. 151-165, 2010.

[16] G. W. Thomas, D. L. Sparks, A. L. Page et al., Soil pH and Soil Acidity. Sparks D Methods of Soil Analysis. Part II, Soil Science Society of America, 1996.

[17] K. J. Beven and M. J. Kirkby, "A physically based, variable contributing area model of basin hydrology," Hydrological Sciences Bulletin, vol. 24, no. 1, pp. 43-69, 1979.
[18] I. D. Moore, R. B. Grayson, and A. R. Ladson, "Digital terrain modelling: a review of hydrological, geomorphological, and biological applications," Hydrological Processes, vol. 5, no. 1, pp. 3-30, 1991.

[19] P. E. Gessler, O. A. Chadwick, F. Chamran, L. Althouse, and K. Holmes, "Modeling soil-landscape and ecosystem properties using terrain attributes," Soil Science Society of America Journal, vol. 64, no. 6, pp. 2046-2056, 2000.

[20] T. R. Marthews, S. J. Dadson, B. Lehner, S. Abele, and N. Gedney, "High-resolution global topographic index values for use in large-scale hydrological modelling," Hydrology and Earth System Sciences, vol. 19, no. 1, pp. 91-104, 2015.

[21] J. L. Deng, A Course in Grey Systems Theory, Press of Huazhong University of Science and Technology, Wuhan, China, 1990.

[22] Y. Lin and S. F. Liu, "A systemic analysis with data (II)," International Journal of General Systems, vol. 29, no. 6, pp. 10011013,2000

[23] S. F. Liu and J. Forrest, "The current development status on Grey System Theory," Journal of Grey System, vol. 19, no. 2, pp. 111-123, 2007.

[24] J. L. Deng, "Introduction to Grey System Theory," The Journal of Grey System, vol. 1, no. 1, pp. 1-24, 1989.

[25] C. L. Lin, "Use of the Taguchi Method and Grey Relational Analysis to optimize turning operations with multiple performance characteristics," Materials and Manufacturing Processes, vol. 19, no. 2, pp. 209-220, 2004.

[26] N. Tosun, "Determination of optimum parameters for multiperformance characteristics in drilling by using grey relational analysis," The International Journal of Advanced Manufacturing Technology, vol. 28, no. 5, pp. 450-455, 2006.

[27] S. F. Liu and Y. Lin, Grey Information: Theory and Practical Applications, Springer, London, UK, 2006.

[28] L. P. Wilding and L. R. Drees, "Spatial variability and pedology," Developments in Soil Science, vol. 11, pp. 83-116, 1983.

[29] P. Adhikari, M. K. Shukla, and J. G. Mexal, "Spatial variability of electrical conductivity of desert soil irrigated with treated wastewater: implications for irrigation management," Applied and Environmental Soil Science, vol. 2011, Article ID 504249, 11 pages, 2011.

[30] M. Aslam and S. A. Prathapar, "Strategies to mitigate secondary salinization in the Indus Basin of Pakistan: a selective review," Tech. Rep. 97, IWMI, 2006.

[31] H. Solomon, Y. Kitamura, Z. Li et al., "Classification of salinization processes in Luohui Irrigation Scheme, China-part of water management research to prevent salinization in semiarid land," Journal of Arid Land Studies, vol. 15, no. 2, pp. 89-105, 2005.

[32] Z. F. Chang, H. Liu, M. Zhao, F. Han, S. Zhong, and J. Tang, "A primary study on the process of formation and succession of desert vegetation in Minqin," Journal of Arid Land Resources and Environment, vol. 21, no. 7, pp. 116-124, 2007. 


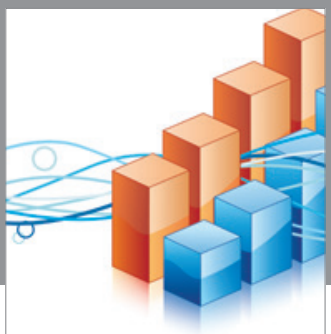

Advances in

Operations Research

vatem alat4

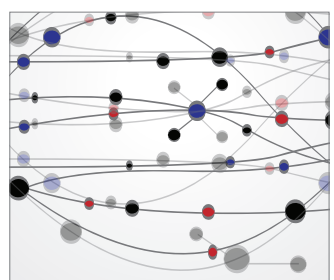

\section{The Scientific} World Journal
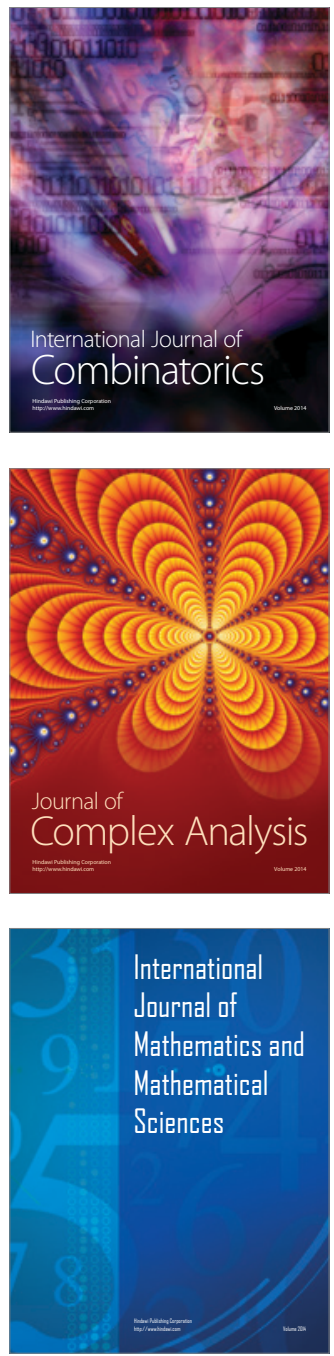
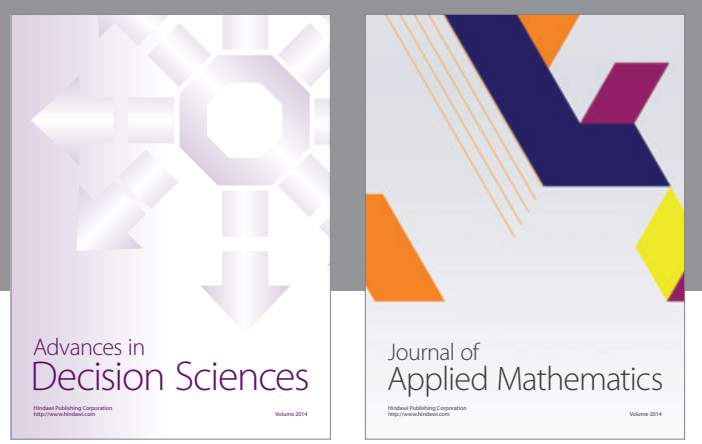

Algebra

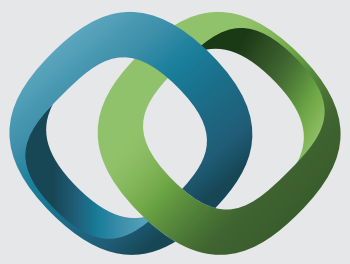

\section{Hindawi}

Submit your manuscripts at

https://www.hindawi.com
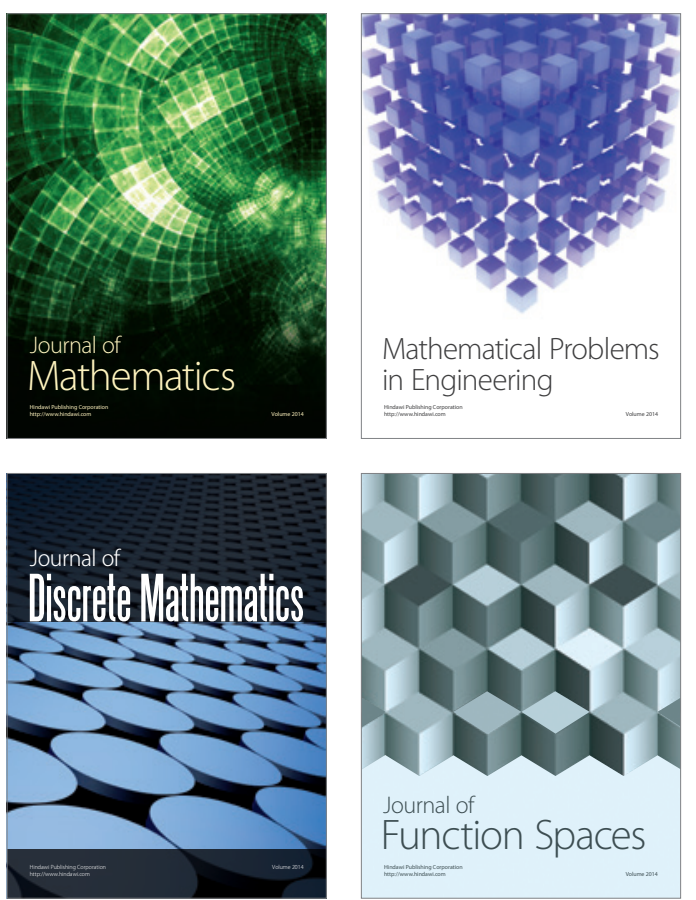

Mathematical Problems in Engineering
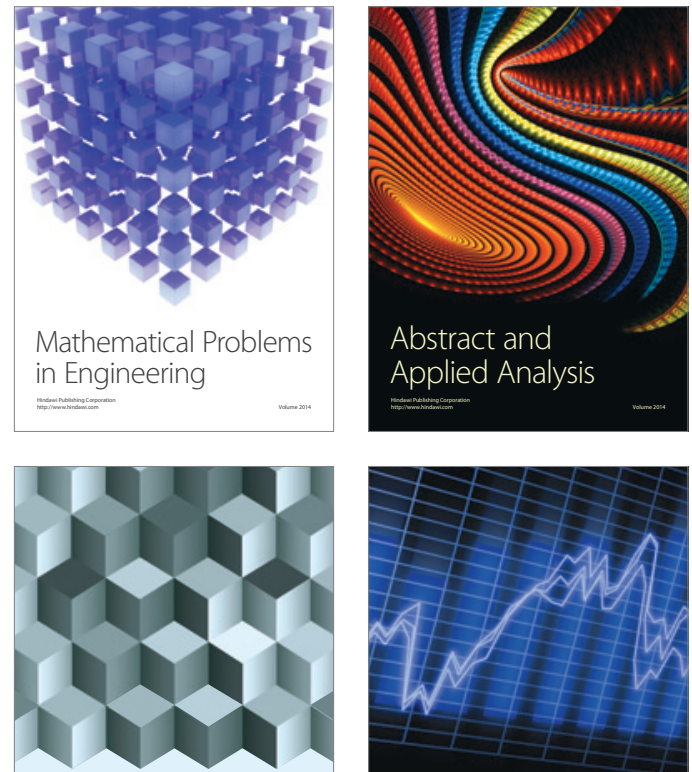

Journal of

Function Spaces

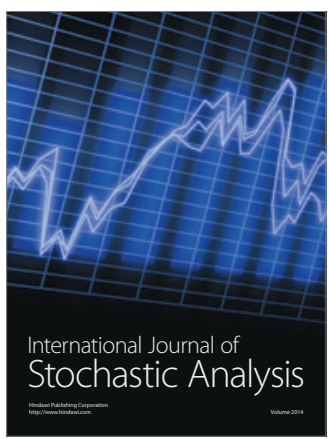

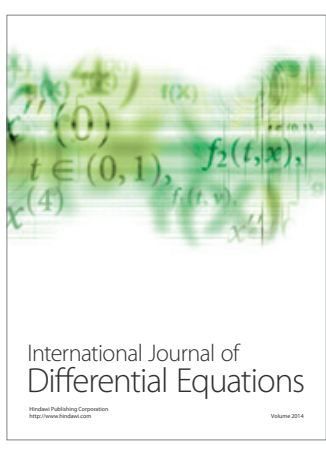
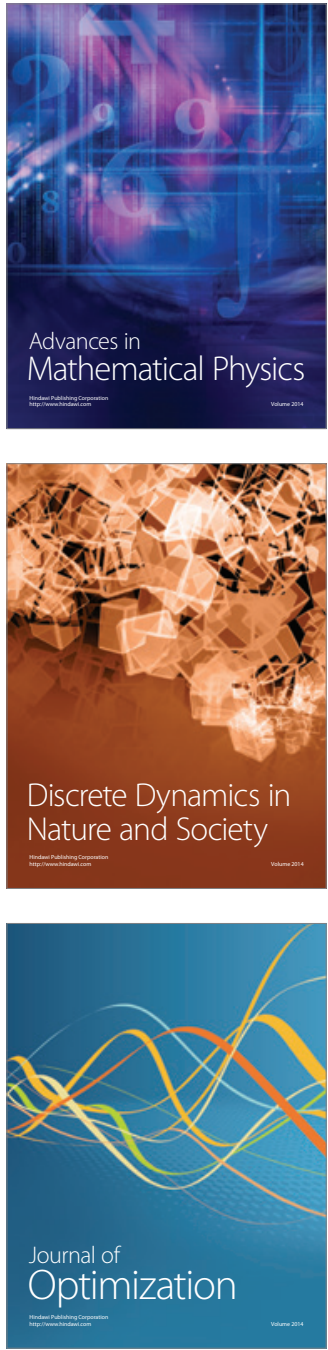